\title{
Design and Numerical Simulation of the Ejector of Pneumatic Conveying System
}

\author{
Zhenhui Luan*, Xu Zhang and Meng Zheng \\ School of Mechanical Engineering, Anhui University of Science and Technology, Huainan 232001, China \\ ${ }^{*}$ Corresponding author
}

\begin{abstract}
Ejector is an important component of pneumatic conveying system and has important influence on the performance of pneumatic conveying system. For the design of the ejector, the system back pressure is generally calculated according to the layout of the pipeline, thus the ejector structure is pushed. On the basis of the comprehensive analysis of current injector theory and design method, the authors put forward a reverse design method of ejector. According to the actual system requirements, the design of the main structure of the injector was calculated by optimizing the structural design method. A 3d modeling tool was used to model the injector, FLUENT software, Euler model and discrete model were used to simulate the internal flow. Considering the influence of different structural parameters on the air transport injector, the static pressure cloud diagram and velocity cloud diagram of solid particles were obtained. The study indicates that the injector designed by the reverse design can meet the requirements of the pneumatic conveying system, and it can promote the application of the ejector in engineering.
\end{abstract}

Keywords—pneumatic conveying system; ejector; reverse design; numerical simulation

\section{INTRODUCTION}

Pneumatic conveying system has been widely used in mineral, power, grain, casting, building materials and other fields because of its more advantages such as safety, simple structure, easy to realize automation, less environmental pollution, and so on [1]. In two-phase flow, because of the complexity of flow, there is no good analytical method to solve some difficult problem, which usually depends on the combination of experiment and theory [2]. In a long period of development, the suspension type of thin phase transport becomes the main method of pneumatic conveying, subsequent, the wear and tear of the pipe is serious, and the energy consumption is higher [3].

As an important part of pneumatic conveying system, gas-solid ejector has attracted more and more attention. The key is how to improve the performance of air-solid ejector. There are many scholars abroad who have done a lot of research on it, such as Weber, Westaway, Bohnet, etc [4]. Flugel designed the first recognized ejector based on mas s equation, momentum equation and energy equation [5]. After the analysis of the momentum conservation and the free flow of turbulent flow, Sokurov improved the design theory of the ejector [6].

\section{DESIGN METHOD OF EJECTOR}

Although the ejectorhas the advantages of simple structure, low pollution and convenient maintenance, however, due to the complexity of internal flow, there is no perfect theoretical calculation method to solve some difficult problem. The design methods of ejectors are mainly based on empirical formulas, experimental coefficients and thermodynamic and hydrodynamic design methods. At present, its design methods generally fall into three categories: empirical coefficient method, classical thermodynamics method and gas dynamic function method.

The main indicators affecting the performance of the injector include below.

The ejection coefficient [6]:

$$
\mu=\frac{\mathbf{G}_{\mathrm{H}}}{\mathbf{G}_{\mathbf{P}}}
$$

Where, $G_{\mathrm{H}}$ is mass flow rate of driving fluid, $\mathrm{kg} / \mathrm{s}$; and $\mathrm{G}_{\mathrm{P}}$ is mass flow rate of working fluid, $\mathrm{kg} / \mathrm{s}$.

Compression ratio:

$$
\mathbf{\Psi}=\frac{\mathbf{P}_{\mathrm{c}}}{\mathbf{P}_{\mathbf{H}}}
$$

Where, $\mathbf{P}_{\mathbf{c}}$ is pressure on the ejector outlet, $\mathrm{Pa} ; \mathbf{P}_{\mathrm{H}}$ is initial pressure of the mixed fluid, $\mathrm{Pa}$.

Work fluid expansion ratio:

$$
\epsilon=\frac{\mathbf{P}_{\mathbf{p}}}{\mathbf{P}_{\mathbf{H}}}
$$

Where, $\mathbf{P}_{\mathbf{p}}$ is pressure of working fluid before nozzle, $\mathrm{Pa}$.

Ejector efficiency:

$$
\eta=\frac{\mu\left(e_{\mathrm{c}}-e_{\mathrm{H}}\right)}{e_{\mathrm{p}}-e_{\mathrm{c}}}
$$


Where, $e_{\mathrm{c}}$ is unit capacity of mixed fluid; $e_{\mathrm{H}}$ is unit capacity of driving fluid; $e_{\mathrm{p}}$ is unit capacity of working fluid.

Parameters affecting the performance of air-solid ejector include:(1) the influence of the larynx distance of the ejector [7]. (2) The influence of system back pressure on ejector. (3) The effect of the contraction angle of the ejector [8].

For design of the ejector, in general, the system back pressure is calculated according to the layout of the pipeline, thus the ejector structure is designed by the back pressure. In this paper, the authors put forward a reverse design method. The outlet pressure value can be calculated by the structure of the ejector. So the ejector should be calculated according to the conveying material, its features and delivery requirements, etc. The work als o include the type selection of fan, the nozzle design and calculation, then mixing tube design calculation, etc.

\section{CALCULATION OF THE EJECTOR}

The diameter of the known material conveying pipe is $50 \mathrm{~mm}$, the speed of material delivery is $20 \mathrm{~m} / \mathrm{s}$, the material gas ratio is 1 , the pressure at the entrance of the fan is 0 , the temperature of fan inlet is $20^{\circ} \mathrm{C}$, and at $20^{\circ} \mathrm{C}$, air tightness is $\rho_{1}=1.2 \mathrm{~kg} / \mathrm{m}^{3}$, and $k=1.4$.

\section{MODEL SELECTION OF ROOTS BLOWER}

The volume flow of the working fluid

$$
V_{f}=\frac{\pi}{4} D^{2} v=\frac{\pi}{4} \times(0.05)^{2} \times 20=0.03927 \mathrm{~m}^{3} / \mathrm{s}=2.3562 \mathrm{~m}^{3} / \mathrm{min}
$$

Mas s flow of working fluid

$$
\mathrm{Q}_{\mathrm{m}}=\rho_{1} \mathrm{~V}_{\mathrm{g}}=1.2 \times 0.03927=0.047124 \mathrm{~kg} / \mathrm{s}
$$

According to the parameters of rotz fan, WHR65 was selected, and its inlet flow is $2.36 \mathrm{~m}^{3} / \mathrm{min}$, pressure rise is $29.4 \mathrm{kPa}$.

Discharge pressure of fan

$$
P_{p}=101.3+29.4=130.7 \mathrm{kP}_{\mathrm{a}}
$$

\section{NOZZLE DESIGN} below

The isentropic relations of air at the nozzle entrance is as

$$
\frac{\mathbf{P}_{\mathbf{p}}}{\rho_{\mathrm{p}}^{k}}=\frac{\mathbf{P}_{1}}{\rho_{1}^{k}}
$$

According to Eq. 5 , the density $\rho_{\mathrm{p}}$ of air at the nozzle entrance can be obtained as $1.44 \mathrm{~kg} / \mathrm{m}^{3}$.

\section{A. The Outlet Diameter of Nozzle}

The outlet diameter of the nozzle can be determined by Eq. 6 .

$$
\mathbf{d}=\sqrt{\frac{4 \rho_{\mathrm{m}}}{\left(\frac{\mathbf{P}_{\mathrm{t}}}{\mathbf{p}_{0}}\right)^{\frac{1}{k}} \sqrt{2 \frac{k}{k-1} \frac{\mathbf{P}_{0}}{\rho_{0}}\left[1-\left(\frac{\mathbf{P}_{\mathrm{t}}}{\mathbf{P}_{0}}\right)^{\frac{k-1}{k}}\right]}}}
$$

After data generation, we can get the outlet diameter of the nozzle as $15.4 \mathrm{~mm}$.

\section{B. Cone Angle and Inlet Diameter of Nozzle}

To determine cone angle as $10^{\circ}$ and inlet diameter as $30 \mathrm{~mm}$.

\section{NUMERICAL SIMULATION OF THE EJECTOR}

The geometric model of the ejector was established in solid works, then the inner cavity of the solid region was drawn out in the Fluid Flow (Fluent) of ANSYS, the mesh was divided by mesh, and named the import and export boundary, the solution process was completed in FLUENT, as shown in Figure I.

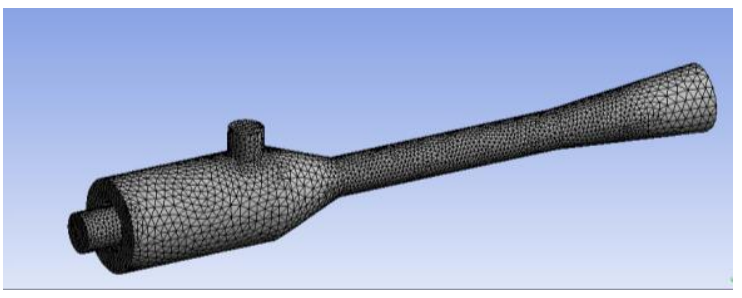

FIGURE I. MODEL OF THE EJECTOR

\section{THE BOUNDARY CONDITIONS}

\section{A. Pressure Inlet}

The pressure change after the nozzle exit is not great, so the gas phase was calculated according to incompressible flow, and inlet pressure is $29.4 \mathrm{kPa}$.

\section{B. Velocity Inlet}

The particle diameter is $0.05 \mathrm{~mm}$, the inlet velocity is $0.08 \mathrm{~m} / \mathrm{s}$, the delivery capacity of material is $0.0422 \mathrm{~kg} / \mathrm{s}$.

\section{Wall}

Standard no-slip wall.

\section{Pressure Outlet}

Considering of the back pressure, the pressure outlet is $6.232 \mathrm{kPa}$. 


\section{CHOICE OF SOLVER}

According to [9], this paper adopted double-fluid model, implicit pressure algorithm, $\mathbf{k}-\varepsilon$ equation, second order and first order windward equation, and the particle density as $1000 \mathrm{~kg} / \mathrm{m}^{3}$.

\section{THE SIMULATION RESULTS}

\section{A. Static Pressure Analysis}

Static pressure in standard operating conditions is shown in Figure II. From Figure II, you can see that the pressure remains unchanged in the straight pipe of the nozzle. The pressure of the working fluid drops when it flows through contraction section of the nozzle. The pressure of the working fluid at the nozzle outlet is equal to one atmospheric pressure. At this time, the pressure of the receiving chamber is basically consistent with the inlet pressure of the solid particles. Under the action of gravity, solid particles can fall into the receiving chamber, and be carried forward under the high speed airflow. The static pressure increases because of the jet action of the gas and the exchange of energy with the solid particles. In mixing chamber, because the pipe diameter is unchanged, the static pressure value is almost constant. With the change of the diameter of the diffuser pipe, the kinetic energy is converted to static pressure and static pressure increases.

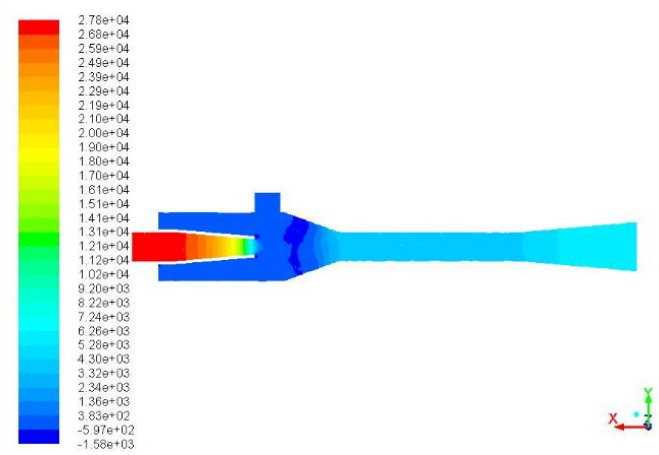

FIGURE II. ST ANDARD ST ATIC PRESSURE CONT OURS

\section{VELOCITY ANALYSIS}

The velocity cloud graph of solid particles is shown in Figure III. FromFigure III, you can see that the solid particles are faster below the axis of the jet zone due to the impact of solid particles and airflow and the weight of solid particles themselves. In the receiving chamber, the velocity of the solid particles in the rear area of the nozzle is close to zero, which indicates that the solid particles are deposited here. In mixing chamber, the velocity distribution of solid particles is relatively uniform, which indicates that the mixing of solid particles and gases tends to balance.

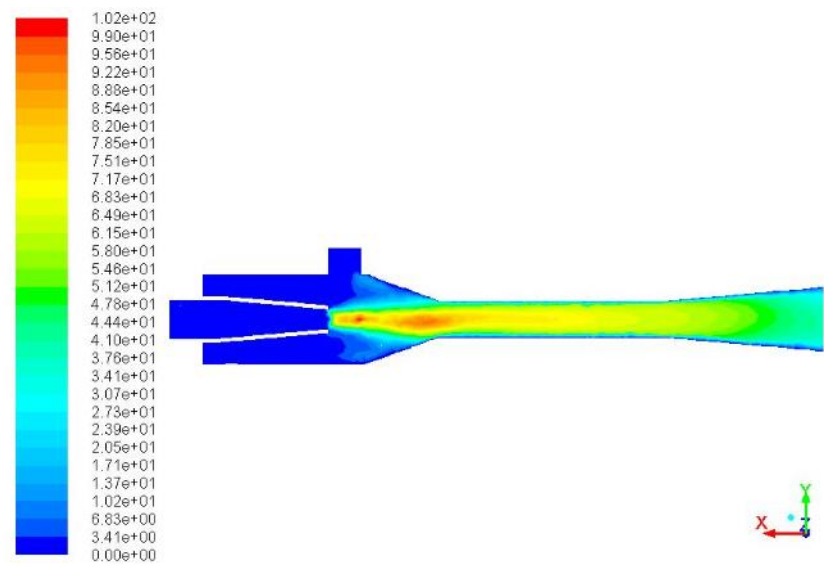

FIGURE III. SOLID PARTICLE VELOCITY CONTOURS

\section{SUMMARY}

A ejector is a key component of pneumatic conveying system. This paper designed a ejector by the reverse design method, established 3D model of the ejector, obtained the pressure and velocity contours diagram of the ejector by FLUENT software, and the work would promote ejector development.

\section{REFERENCES}

[1] Lun Yang, Yihua Xie. Pneumatic Conveying Engineering. Mechanical industry press, 2006.1 (In Chinese).

[2] Xianzhou Cao, Xuanmin Lu. The Development of Pneumatic Conveying Technology and Its Application in Grain Industry. Food and Feed Industry, 2011(6):16 (In Chinese).

[3] Xianghun Liu, Lei Shi, Xuchang Xu. The Research Status of the Dense Gas Solid Two-phase Flow Euler-Lagrangian Method Is Studied Journal of Computational Mechanics, 2007, 24(2):166-172 (In Chinese).

[4] Bohnet M, Wagenknecht U.Investigation on Flow Conditions in Gas/solid- Injectors. German Chemical Engineering, 1978, 1(5): 298304

[5] Jiang L. Recent Development in Ejector Technology-A Review. International Journal of Ambient Energy, 2005, 26(1):13-26.

[6] Sokolow, Qiuyun Huang Translation. Ejector. Science Press, 1977 (In Chinese).

[7] Weixiong Chen, Huiqiang Chen, Chaoyin Shi. Experimental Study on the Influence of the Nozzle Spacing on the Performance of the Injector. Journal of Chinese Academy of Sciences, 2016, 33(2):253-257 (In Chinese).

[8] Rui Xu, Changlong Du, Rui Ceng. Study on the Jet Flow Simulation of Different Angle Nozzles. Mining Machinery, 2011, 39(2):36-39 (In Chinese).

[9] Haowei Wang, Hua Zhu, Zhihua Zhong. Three-dimensional Numerical Simulation of Air-solid Ejector. Energy Research and Utilization, 2008(1):17-21 (In Chinese). 